\title{
Self- Representation di Era Digital (Analisis Semiotika Acara TV Black Mirror Episode Nosedive)
}

\author{
Clarisa Tan, Wulan Purnama Sari \\ clarisarachel@gmail.com,wulanp@fikom.untar.ac.id
}

Fakultas Ilmu Komunikasi, Universitas Tarumanagara, Jakarta

\begin{abstract}
The rise of technology and information makes it easier for humans to communicate, introducing new aspects about the relationship between individual freedom and technology. Digital technology and social media are very influential in everyday life, communication between family and friends is not limited by geographical challenges. Social media makes it easier to express and understand ourselves through online communities. This research aims to see how self-representation in the digital era is shown through Netflix TV show Black Mirror episode Nosedive by Charlie Brooker. The researcher conducted a semiotic analysis on the first episode in Season 3, "Nosedive," regarding the self-representation shown and how the relationship was created through social media in all Lacie Pound's relationships. Obsessed with social rankings Lacie must carry out positive interactions and represent herself according to social standards. Rating values in Nosedive make relationships between people seem fake because they are concerned with the judgments given to each other. All people in the world must follow the existing social standards or they can be exiled because they have low ratings. Nosedive mimics the real life problem of obsession with social achievement through cognitive alienation, that tells their current excitement with digital and social connectivity. This study uses Charles Sanders Peirce's semiotics theory with a qualitative research method approach. Researchers collect data by observation and documentation, library research and online sources.
\end{abstract}

Keywords: black mirror, nosedive, relationship, self-representation, social media.

\begin{abstract}
Abstrak
Munculnya teknologi dan informasi memudahkan manusia untuk berkomunikasi, memperkenalkan aspek-aspek baru tentang hubungan antara kebebasan individu dan teknologi. Teknologi digital dan media sosial sangat berpengaruh dalam kehidupan seharihari, komunikasi antara keluarga dan teman tidak dibatasi oleh tantangan geografis. Media sosial memudahkan mengekspresikan dan memahami diri kita sendiri melalui komunitas online. Penelitian ini bertujuan untuk melihat bagaimana self-representasi di era digital yang ditunjukan dalam acara TV Black Mirror episode Nosedive karya Charlie Brooker. Penulis melakukan analisis semiotika pada episode pertama di Musim 3, "Nosedive," mengenai self-representasi yang ditunjukan dan bagaimana hubungan yang diciptakan terhadap melalui media sosial dalam semua hubungan Lacie Pound. Terobsesi dengan peringkat sosial Lacie harus melakukan interaksi positif dan merepresentasikan dirinya sesuai dengan standar sosial. Peringkat nilai dalam Nosedive membuat hubungan antar masyarakat menjadi palsu karena mereka mementingkan penilaian yang diberikan satu sama lain. Semua masyarakat dalam dunia itu harus mengikuti standar sosial yang ada atau mereka dapat diasingkan karena memiliki penilaian yang rendah. Nosedive meniru masalah
\end{abstract}


kontemporer obsesi prestasi sosial melalui pengasingan kognitif, yang menceritakan kegembiraan mereka saat ini dengan konektivitas digital dan sosial. Penelitian ini menggunakan teori semiotika Charles Sanders Peirce dengan pendekatan penelitian metode kualitatif. Peneliti mengumpulkan data dengan observasi dan dokumentasi, studi pustaka dan sumber online.

Kata Kunci: black mirror, hubungan, media sosial, nosedive, self-representasi.

\section{Pendahuluan}

Selama ribuan tahun, manusia telah menggunakan media untuk merepresentasikan diri mereka sendiri. Generasi saat ini mengunggah foto selfie ke instagram atau snapchat dan menulis update di facebook atau tumblr, dengan media sosial, orang-orang biasa berbagi self-representasi mereka dengan audiens yang lebih besar daripada sebelumnya (Rettberg, 2016).

Digital self-presentation adalah istilah yang digunakan saat menampilkan kepribadian, preferensi, atau gaya hidup seseorang secara online (Sung, et al., 2016). Menurut Rettberg (2016) digital self-representation adalah percakapan yang memungkinkan suara baru didengar. Namun, masyarakat mendisiplinkan representasi digital seperti selfie dan blog. Rettberg (2016) menjelaskan bahwa representasi adalah objek, tanda yang dipandang dibangun dengan cara tertentu, baik selfie maupun tweet adalah ekspresi dari representasi diri. Sedangkan presentasi adalah tindakan untuk mempresentasikannya.

Media sosial membuka tempat dimana individu dapat mencari konfirmasi dan validasi melalui persetujuan dan pendapat orang lain (Bazarova dan Choi, 2014). Manusia juga berbagi lebih banyak secara online (Brandt, 2014; Zigterman, 2013), seperti kehidupan sehari-hari, dan kadang-kadang berbagi untuk menampilkan diri sendiri dalam cahaya yang cerah. Memberi peringkat satu sama lain, keinginan untuk menyoroti fitur terbaik yang dimiliki, dan pada gilirannya menghasilkan sikap fake it till you make it.

Pada acara TV Black Mirror yang muncul di Netflix bentuk selfrepresentation di era digital sangat jelas digambarkan pada episode Nosedive. Black Mirror adalah seri antologi yang memanfaatkan kegelisahan kolektif manusia dengan dunia modern, masing-masing episode bersifat stand-alone menceritakan sebuah kisah yang tajam dan menegangkan menjelajahi tema-tema techno-paranoia kontemporer. Judulnya, Black Mirror, mengacu pada cara tampilan layar ponsel, komputer, dan televisi saat dimatikan. Teknologi telah mengubah semua aspek kehidupan manusia; di setiap rumah; di setiap meja; di setiap telapak tangan - layar plasma; sebuah monitor; Smartphone - Black Mirror mencerminkan keberadaan Abad 21 manusia. Serial ini dibuat dan ditulis oleh Charlie Brooker, dan eksekutif diproduksi oleh Brooker dan Annabel Jones (Sumber: insider.com dan rottentomatoes.com).

Salah satu aspek yang sering tampak dalam interaksi sosial adalah keinginan untuk menciptakan kesan yang baik bagi orang lain (Nezlek \& Leary, 2002). Penggunaan media sosial telah menjadi tren global, orang-orang berpartisipasi dalam kegiatan sosial online dengan mewakili diri mereka sendiri sehingga 
representasi diri sudah merupakan syarat partisipasi dalam situs jejaring sosial (Thummim, 2012).

Berdasarkan pemaparan diatas, hal yang membuat penulis tertarik melakukan penelitian adalah self representasi di era digital dalam acara TV Black Mirror episode Nosedive. Karena itu, penulis ingin mengangkat masalah ini sebagai bahan pembuatan penulisan ilmiah dengan judul "self-representasi di era digital (Analisis Semiotika acara TV Black Mirror episode Nosedive).

Tujuan penelitian yang ingin dicapai dalam penelitian ini adalah untuk mengetahui bagaimana self-representation di era digital ditampilkan dalam acara TV Black Mirror episode Nosedive.

Penelitian analisis semiotika Charles Peirce ini menggunakan beberapa teori seperti, teori komunikasi massa (Romli, 2016) karena dalam penelitian ini acara TV Black Mirror episode Nosedive merupakan sebuah media massa yang menyampaikan pesan kepada penonton dan media sosial merupakan media massa. Peneliti menggunakan teori dramaturgi Erving Goffman (1959) yang dapat membantu dengan menjelaskan self-representasi yang ditunjukan oleh karakter dan menjelaskan mengapa karakter sangat mementingkan penilaian.

Penulis mengambil penelitian Wulan Purnama Sari (2015), Konflik Budaya Dalam Konstruksi Kecantikan Wanita Indonesia (Analisis Semiotika Dan Marxist Iklan Pond's White Iklan Pond's White Beauty Versi Gita Gutawa) sebagai referensi dan acuan dalam penelitian ini. Perbedaan penelitian terdahulu sebelumnya ialah Wulan Purnama Sari (2015) membahas mengenai konstruksi kecantikan dan stereotip gambaran kecantikan bagi perempuan Indonesia dalam iklan Pond's White Beauty sedangkan penulis melakukan penelitian selfrepresentasi di era digital dalam acara TV Black Mirror episode Nosedive.

\section{Metode Penelitian}

Pada penelitian ini, penulis menggunakan pendekatan metode kualitatif. Pendekatan kualitatif menekankan analisis proses dari proses berpikir secara induktif yang berkaitan dengan dinamika hubungan antar fenomena yang diamati, dan senantiasa menggunakan logika ilmiah (Gunawan, 2013). Menurut Bogdan dan Taylor (Moleong, 2012) penelitian kualitatif adalah sebagai prosedur penelitian yang menghasilkan data deskriptif berupa kata-kata tertulis atau lisan dari orangorang dan perilaku yang dapat diamati. Pada pendekatan ini, peneliti membuat suatu gambaran yang kompleks, meneliti kata-kata, laporan terinci dari pandangan informan, dan melakukan studi pada situasi sosial yang alami (Bungin, 2007).

Penulis menggunakan metode analisis semiotika dengan menggunakan pendekatan analisis semiotik Charles Sanders Peirce. Peirce menandaskan bahwa manusia hanya dapat berpikir dengan medium tanda. Manusia hanya dapat berkomunikasi lewat sarana tanda. Tanda dalam kehidupan manusia terdiri dari berbagai macam, antara lain tanda gerak ataupun isyarat, tanda verbal yang dapat berupa ucapan kata, maupun tanda non-verbal yang berupa bahasa tubuh (Sobur, 2012). 
Teknik analisis data yang akan digunakan dalam penelitian ini, yaitu dengan menggunakan semiotika dengan pendekatan Peirce. Berdasarkan analisis semiotika menurut Charles Sanders Peirce makna terdiri atas:

1. Tanda (Sign): sesuatu yang berbentuk fisik yang dapat ditangkap oleh panca indra manusia dan merupakan sesuatu yang merujuk hal lain diluar tanda itu sendiri.

2. Objek (object): kontek sosial yang menjadi referensi dari tanda atau suatu yang merujuk tanda.

3. Interpretan (interpretant): interpretasi, penafsiran, pemahaman seseorang tentang tanda.

\section{Hasil Penemuan dan Diskusi}

Penulis menemukan 12 scene dalam acara TV Black Mirror episode Nosedive yang mengindikasikan self-representasi di era digital yang telah dianalisis menggunakan teori semiotika Charles Peirce. Tabel analisis 1 sampai 12 menunjukan bahwa karakter Lacie Pound terobsesi untuk mendapatkan peringkat tinggi pada sistem peringkat masyarakat tersebut. Peringkat media sosial terkoneksi dengan peringkat dalam dunia nyata, seperti sistem kelas sosial. Masyarakat dengan peringkat tinggi dapat memiliki banyak keuntungan seperti; diskon rumah, akses pekerjaan, upgrade kelas pesawat, dan lain-lain.

Lacie harus menempatkan dirinya dengan orang-orang kelas atas untuk mendapatkan popularitas dan meningkatkan poinnya dengan cepat. Lacie berusaha untuk mendapatkan popularitas dengan memposting lebih banyak cerita, interaksi positif, dan ia harus merepresentasikan dirinya yang sesuai dengan standar sosial yang diterima secara umum. Sepanjang episode, Lacie menjadi begitu terperangkap dalam peringkatnya, menampilkan citra dan gaya hidup yang dipaksakan untuk menerima peringkat yang lebih tinggi. Saat Lacie menolak sistem peringkat dalam masyarakat itu ia lepas kendali dan menunjukan sisi dirinya yang tidak pernah ia tunjukan kepada orang lain. Setelah implan retina dan gadget dilepas ia merasa bebas dan tidak mengkhawatirkan peringkatnya sehingga ia bisa berkata dan berbuat sesukanya.

Tabel 1. Analisis Semiotika Nosedive

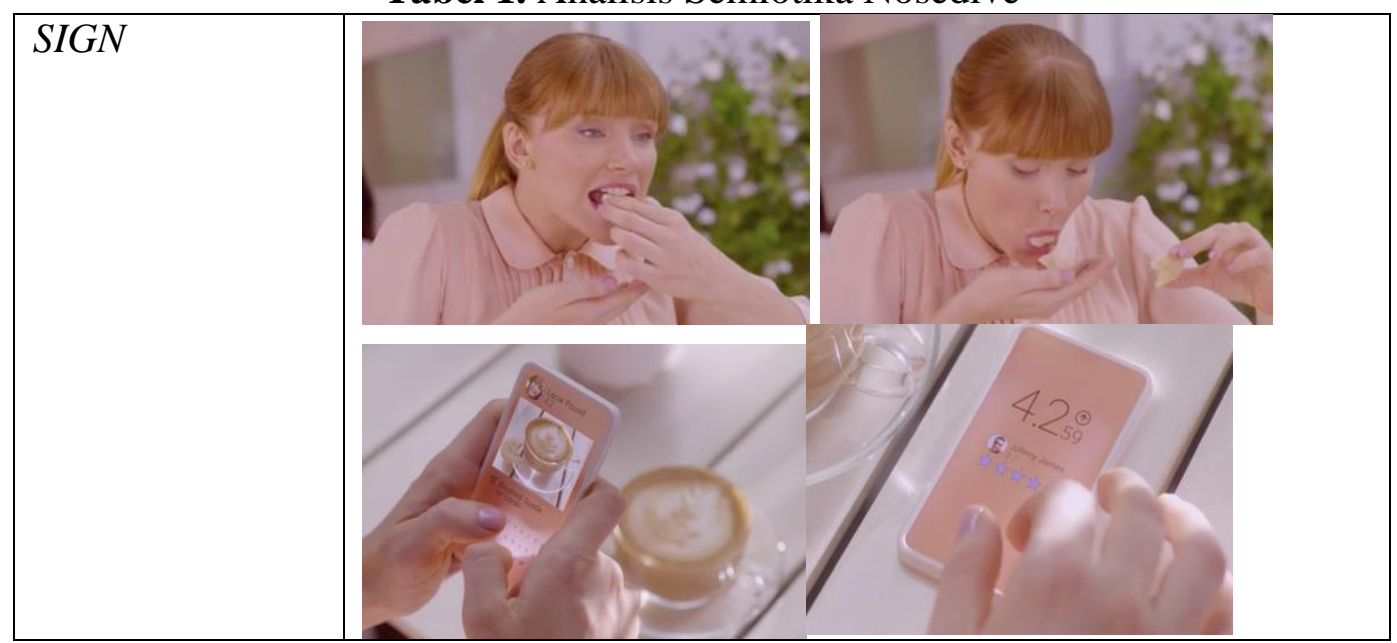




\begin{tabular}{|l|l|}
\hline OBJECT & $\begin{array}{l}\text { Seorang perempuan menggigit biskuit dan langsung } \\
\text { memuntahkannya dengan raut wajah meringis lalu } \\
\text { mengambil foto biskuit tersebut dan mempostingnya untuk } \\
\text { menaikkan ratingnya. }\end{array}$ \\
\hline INTERPRETANT & $\begin{array}{l}\text { Dari raut wajah Lacie dapat diketahui bahwa biskuit dan kopi } \\
\text { yang dibelinya tidak enak, tetapi Lacie tetap memposting } \\
\text { biskuit dan kopi tersebut dengan emoji senyum untuk } \\
\text { mendapatkan penilaian. Makanan telah menjadi bagian besar } \\
\text { jejaring sosial dengan mengambil foto makanan orang-orang } \\
\text { mempostnya tidak hanya untuk diri mereka sendiri, tetapi } \\
\text { juga untuk dibagikan kepada orang lain dengan memposting } \\
\text { foto makanan lebih mudah untuk menjangkau orang lain } \\
\text { Lacie membagikan foto makanannya, ia dapat mendapat } \\
\text { perhatian dari orang-orang (aglow.com \& bu.edu). }\end{array}$ \\
\hline
\end{tabular}

Self-representasi di era digital dalam Nosedive menggambarkan individual yang serupa. Berpakaian dengan skema warna serupa, berperilaku serupa yang sesuai dengan standar mereka. Hubungan mereka akan satu sama lain menjadi palsu karena satu sama lain berusaha untuk mendapatkan peringkat tinggi setelah interaksi mereka bukannya menciptakan interaksi yang asli.

Sistem peringkat dalam Nosedive membuat semua manusia menjadi aktor dalam kehidupan mereka untuk menciptakan kesan tertentu pada orang lain. Hubungan kehidupan nyata manusia menjadi dangkal karena orang lebih peduli tentang mendapatkan peringkat tinggi dari satu sama lain, daripada memiliki interaksi nyata.

Tabel 2. Analisis Semiotika Nosedive

SIGN




\begin{tabular}{|l|l|}
\hline OBJECT & $\begin{array}{l}\text { Seorang perempuan membacakan pidatonya dengan sangat } \\
\text { dramatis dan berlinang air mata di depan seorang lelaki. } \\
\text { Mereka bertengkar dan berujung dengan memberikan } \\
\text { penilaian yang jelek satu sama lain. }\end{array}$ \\
\hline INTERPRETANT & $\begin{array}{l}\text { Menurut Ryan, pidato Lacie terlalu berlebihan dan berusaha } \\
\text { terlalu keras untuk mengesankan kaum 4,5 keatas. Ryan } \\
\text { merasa Lacie telah berubah sejak ia terlalu fokus dengan } \\
\text { penilaiannya. Lacie sangat mengandalkan pidatonya, ia } \\
\text { berharap dengan menampilkan pidato yang menyentuh maka } \\
\text { ia akan mendapatkan rating tinggi dari para peringkat 4,5 } \\
\text { keatas. Perilaku Lacie offline di rumah dan dirinya online } \\
\text { adalah perilaku yang sangat kontras. Front-stage Lacie adalah } \\
\text { versi yang dipercaya akan menguntungkan bagi orang lain } \\
\text { karena sikapnya dan cara dia membawa dirinya. Hal ini dapat } \\
\text { membantu mengelola kesan saat bertemu dengan orang lain. } \\
\text { Dirinya sendiri di rumah merasa nyaman dan membuat } \\
\text { kesalahan dengan meneriaki adik laki-lakinya adalah dirinya } \\
\text { di backstage. }\end{array}$ \\
\hline
\end{tabular}

Dalam kehidupan karakter Nosedive sehari-hari mereka membentuk perilaku dan penampilan untuk mengendalikan cara orang lain memandangnya (Goffman, 1995). Manusia memakai "wajah", topeng, yang berbeda di semua situasi sosial. Penonton mendapatkan akses ke tahap "front" yang merupakan cara setiap individu menempatkan dirinya, seperti halaman profil media sosial. Manusia mendapatkan perasaan memiliki melalui interaksi sosial ini. Tetapi hal pertama yang menjadi fokus mereka adalah bagaimana orang lain memandang mereka karena penilaian dalam dunia itu sangat penting.

\section{Simpulan}

Acara Netflix Black Mirror menggambarkan kenyataan dimana media dan teknologi telah mengambil alih kehidupan manusia. Manusia saat ini telah memodifikasi representasi diri mereka agar lebih sesuai dengan ranah online tempat jutaan orang menunggu untuk dinilai dan menilai seseorang. Manusia membentuk dan menciptakan diri idealnya untuk disajikan di media sosial, dan berusaha meningkatkan popularitas diri melalui pengembangan brand pribadi diri. Peringkat pada manusia tidak menghasilkan keaslian di dunia. Peringkat membuat seseorang 
mulai menghabiskan hidup mereka, dan setiap tindakan yang mereka lakukan dimotivasi oleh keinginan mereka untuk mendapatkan status dan peringkat yang lebih tinggi. Hal ini merupakan obsesi yang dimiliki banyak orang saat ini tentang bagaimana orang lain melihatnya melalui media sosial. Kehidupan manusia ditentukan oleh peringkat mereka, mereka kehilangan rasa individualitas mereka daripada menunjukan diri mereka sendiri. Setiap karakter hidup untuk menyenangkan orang lain. Lacie memasuki setiap situasi yang ditentukan untuk menyenangkan orang-orang di sekitarnya dan menerima peringkat tinggi dalam hidup sebagai dirinya sendiri.

Sistem peringkat dalam Nosedive menyerupai platform media sosial kita saat ini. Banyak manusia tampaknya lebih peduli dengan kehidupan online, daripada yang sebenarnya dijalani. Filter dapat menjadi alat yang berguna untuk membuat foto Instagram menjadi lebih menarik, tetapi dapat juga terlibat dengan menyaring kehidupan manusia di media sosial. Memposting foto untuk menunjukkan betapa hebatnya hidup seseorang ketika sebenarnya manusia hanya mengedepankan yang terbaik secara online, memangkas hal-hal buruk. Secara terus menerus manusia memeriksa profil media sosial, untuk melihat berapa banyak like yang didapatkan, dan apakah ada seseorang yang memposting sesuatu yang menarik karena manusia terobsesi dengan media sosial.

\section{Ucapan Terima Kasih}

Penulis ingin berterima kasih sebesar-besarnya kepada semua pihak yang telah mendukung, dan membantu penulis dalam menyelesaikan penelitian ini sampai selesai.

\section{Daftar Pustaka}

Bazarova, N.N., and Choi, Y.H. (2014). Self-disclosure in social media: Extending the functional approach to disclosure motivations and characteristics on social network sites, Journal of Communication, vol. 64, pp. 635-657.

Brandt, R. (2014). Google divulges numbers at I/O: 20 bullion texts, 93 million selfies and more (online). http://www.bizjournals.com/sanjose/news/2014/06/25/google-divulgesnumbers-at-i-o-20-billion-texts-93.html\%3E (diakses: 16 Agustus 2019)

Bungin, Burhan. (2007). Penelitian Kualitatif : Komunikasi, Ekonomi, Kebijakan Publik, dan Ilmu Sosial Lainnya. Jakarta: Kencana Prenada Media Group

Goffman, Erving. (1959). The Presentation of Self in Everyday Life. Jakarta: Erlangga.

Gunawan, Imam. (2013). Metode Penelitian Kualitatif: teori dan praktik. Jakarta: Bumi Aksara.

Moleong, Lexy. (2012). Metodologi Penelitian Kualitatif. Bandung: PT Remaja Rosdakarya Offset.

Nezlek, J. B., \& Leary, M. R. (2002). Individual differences in self-presentational motives in daily social interaction. Personality \& Social Psychology Bulletin, 28, 211-223. 
Rettberg, J. W. (2014). Seeing ourselves through technology: How we use selfies, blogs and wearable devices to see and shape ourselves. Springer (online). https://link.springer.com/content/pdf/10.1057/9781137476661_1.pdf (diakses: 16 Agustus 2019)

Romli, Khomsahrial, (2016). Komunikasi Massa. Jakarta: PT. Gramedia Grasindo Gramedia Widiasarana Indonesia

Rotten Tomatoes. (n.d). Black Mirror. (online). https://www.rottentomatoes.com/tv/black_mirror (diakses: 30 Agustus 2019)

Sari, Wulan Purnama. (2015). Konflik Budaya Dalam Konstruksi Kecantikan Wanita Indonesia (Analisis Semiotika Dan Marxist Iklan Pond's White Beauty Versi Gita Gutawa). (online). https://journal.untar.ac.id/index.php/komunikasi/article/view/18/39 (diakses: 6 Desember 2019)

Sobur, A. (2012). Analisis Teks Media : Suatu Pengantar Analisis Wacana, Analisis Semiotika, dan Analisis Framing. Bandung : Remaja Rosdakarya.

Sung, Y., Lee, J-A., Kim, E., and Choi, S-M. (2016) Why we post selfies: Understanding motivations for posting picture of oneself, Journal of Personality and Individual Differences, vol. 97, pp.260-265.

Thumim, Nancy. (2012). Self-Representation and Digital Culture. (online). https://link.springer.com/book/10.1057/9781137265135 (diakses: 16 Agustus)

Urie, C. 2019. 10 surprising things you didn't know about 'Black Mirror'. (online). https://www.insider.com/black-mirror-fun-facts-2018-10\#the-name-blackmirror-refers-to-a-blank-video-screen-3 (diakses: 15 Oktober 2019)

Zigterman, B. (2013). Number of photos taken in 2014 will approach 1 trillion thanks to selfie explosion. (online) http://bgr.com/2013/12/24/how-manyselfies-were-taken-in-2013/\%3E (diakses: 16 Agustus 2019) 